\title{
Re-lectotypification of Shivparvatia glanduligera, the type of the genus Shivparvatia (Alsineae, Caryophyllaceae)
}

\author{
Bine Xue', Long-Yuan Wang', Gang Yao² \\ I College of Horticulture and Landscape Architecture, Zhongkai University of Agriculture and Engineering, \\ Guangzhou 510225, China 2 College of Forestry and Landscape Architecture, South China Agricultural Uni- \\ versity, Guangzhou 510642, China
}

Corresponding author: Gang Yao (gyao@scau.edu.cn)

Academic editor: G. del Galdo | Received 16September 2020 | Accepted 28 October 2020 | Published 13 November 2020

Citation: Xue B, Wang L-Y, Yao G (2020) Re-lectotypification of Shivparvatia glanduligera, the type of the genus Shivparvatia (Alsineae, Caryophyllaceae). PhytoKeys 166: 129-134. https://doi.org/10.3897/phytokeys.166.58710

\begin{abstract}
The genus Shivparvatia Pusalkar \& D.K. Singh was described in 2015 and the specimen J.D. Hooker 11 deposited in K (K000742193) was designated as the lectotype of its type species $S$. glanduligera (Edgew.) Pusalkar \& D.K. Singh (三 Arenaria glanduligera Edgew.). Nevertheless, J.D. Hooker 11 (K000742193) is actually the type of $S$. ciliolata (Edgew.) Pusalkar \& D.K. Singh (三 Arenaria ciliolata Edgew.). Thus the lectotypification of $S$. glanduligera was problematic and a re-lectotypification for this species is needed. One of the syntypes of S. glanduligera collected from Kashmir (H. Falconer s.n., K000742189) is selected here as its lectotype. Morphologically, S. ciliolata and S. glanduligera can be easily distinguished from each other by their different morphology of indumentum, disc gland and sepals, as well as the color of petals.
\end{abstract}

\section{Keywords}

Arenaria, nomenclature, taxonomy

Copyright Bine Xue et al. This is an open access article distributed under the terms of the Creative Commons Attribution License (CC BY 4.0), which permits unrestricted use, distribution, and reproduction in any medium, provided the original author and source are credited. 
The genus Arenaria L. s.l. includes over 300 species of herbs widely distributed from Northern Temperate to arctic regions (McNeill 1962; Wu et al. 2001). It was divided into ten subgenera traditionally based on the morphology of sepals and petals, as well as the number of styles and lobes at the top of capsules (McNeill 1962). A series of recent molecular phylogenetic studies have made great progress in clarifying the circumscription of Arenaria s.l. (Harbaugh et al. 2010; Greenberg and Donoghue 2011; Sadeghian et al. 2015), and resulted in the disintegration of this large genus and some of its subgenera or sections were elevated as independent genera (Pusalkar and Singh 2015; Sadeghian et al. 2015).

Based on phylogenetic results, Sadeghian et al. (2015) raised the subgenus Solitaria McNeill of Arenaria s.l. to generic rank and described it as a new genus Solitaria (McNeill) Sadeghian \& Zarre, with three species of subgenus Solitaria sampled in their study transferred to this new genus, viz. Solitaria ciliolata (Edgew.) Sadeghian \& Zarre, S. glanduligera (Edgew.) Sadeghian \& Zarre, and S. stracheyi (Edgew.) Sadeghian $\&$ Zarre. They also lectotypified these species except $S$. glanduligera, but three syntypes of its basionym, viz. Arenaria glanduligera Edgew., were cited.

On the other hand, Pusalkar and Singh (2015) elevated the subgenus Solitaria to be a new genus and described it as Shivparvatia Pusalkar \& D.K. Singh three months earlier than Sadeghian et al. (2015). Thus the generic name Shivparvatia has priority in taxonomy. Pusalkar and Singh (2015) also transferred the three species of the subgenus Solitaria to their new genus, viz. Shivparvatia ciliolata (Edgew.) Pusalkar \& D.K. Singh, S. glanduligera (Edgew.) Pusalkar \& D.K. Singh, S. stracheyi (Edgew.) Pusalkar \& D.K. Singh. They further designated the species $S$. glanduligera as the type of Shivparvatia and lectotypified $S$. glanduligera. However, they didn't lectotypify the other two species.

In Pusalkar and Singh (2015), the Indian specimen J.D. Hooker 11 deposited in K (K000742193, Fig. 1A) was designated as the lectotype of Shivparvatia glanduligera, and the other three specimens labeled as GH00353887, K000742194 (Fig. 1C) and K000742195 (Fig. 1B) were cited as isolectotypes of the species. After careful examination of the above mentioned specimens and relevant literature, we found that the four specimens cited in Pusalkar and Singh (2015) all represented S. ciliolata rather than S. glanduligera. The collection J.D. Hooker 11 was actually the type of S. ciliolata (Edgeworth \& Hooker, 1874), and the two specimens K000742194 and GH00353887 had been designated as the lectotype and isolectotype of $S$. ciliolata, respectively, by Sadeghian et al. (2015). The last specimen K000742195 (J.F. Duthie 2760, Fig. 1B) collected from Kumaun actually doesn't share the same collector, collection number and locality with the other three specimens cited in Pusalkar and Singh (2015).

It is therefore obvious that the lectotypification of Shivparvatia glanduligera by Pusalkar and Singh (2015) is problematic, thus a re-lectotypification of this species should be conducted. The basionym of $S$. glanduligera, viz. Arenaria glanduligera, was published based on three specimens: H. Falconer s.n. (K000742189, Fig. 2); J.D. Hooker s.n. (K, Fig. 3); R. Strachey \& J.E. Winterbottom s.n. (K, Fig. 4) (Edgeworth and Hooker 1874). We therefore reselected one specimen from the syntypes of $S$. glanduligera as its lectotype. As only the specimen $H$. Falconer s.n. has been assigned a barcode number (K000742189), it is therefore selected. 


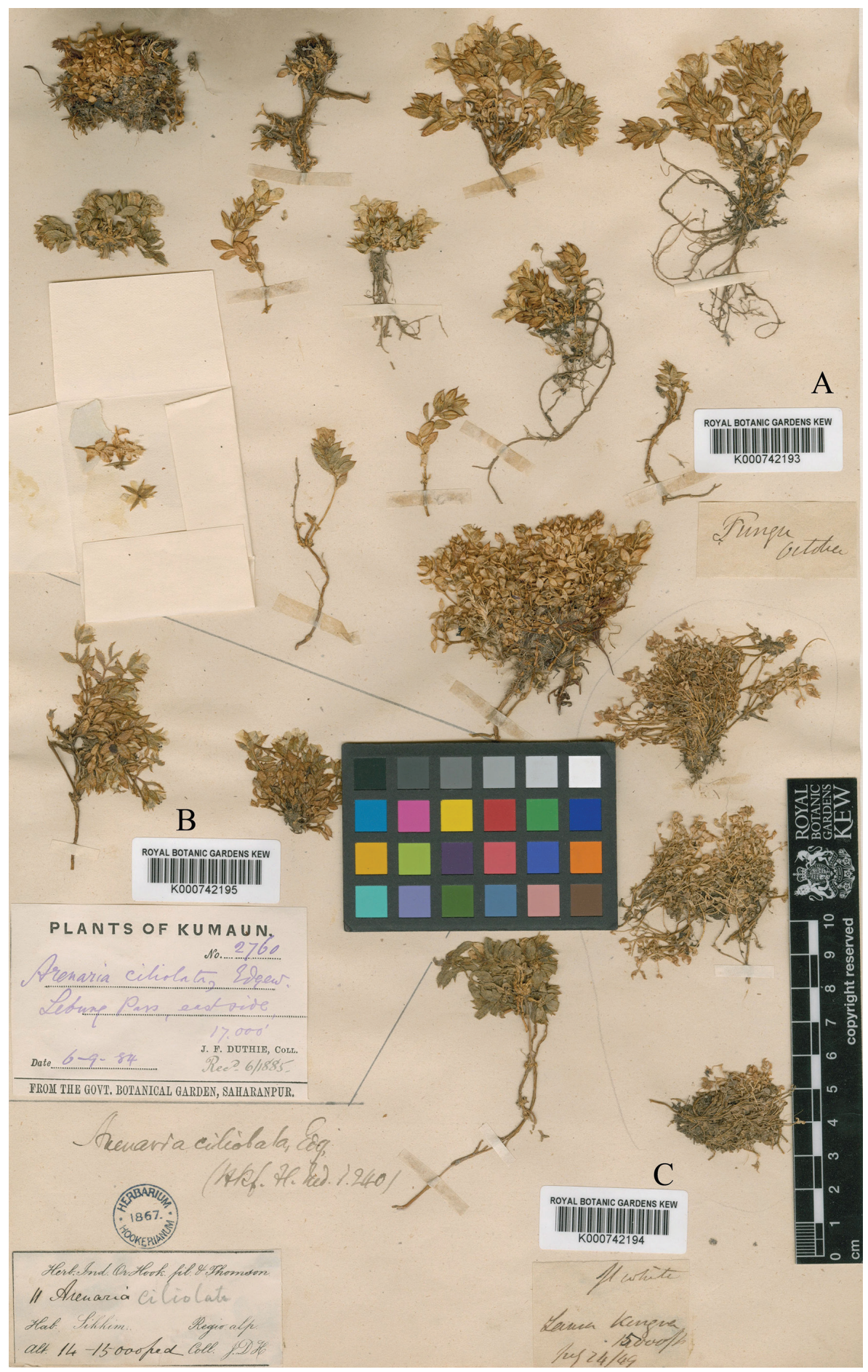

Figure I. Specimens of Solitaria ciliolata (Edgew.) Sadeghian \& Zarre A Isolectotype of S. ciliolata (J.D. Hooker 11, K000742193) B J.E. Duthie 2760 (K000742195) C lectotype of S. ciliolata (J.D. Hooker 11, K000742194; designated by Sadeghian et al. 2015). 


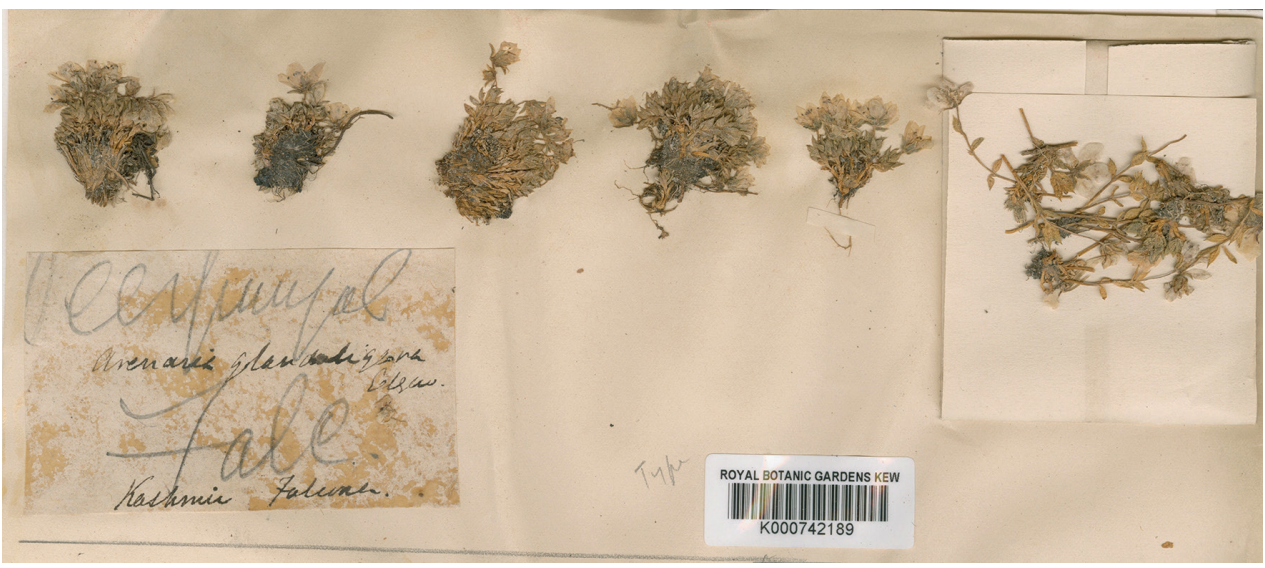

Figure 2. Lecotype of Shivparvatia glanduligera (Edgew.) Pusalkar \& D.K. Singh from Kashmir (H. Falconer s.n., K000742189).

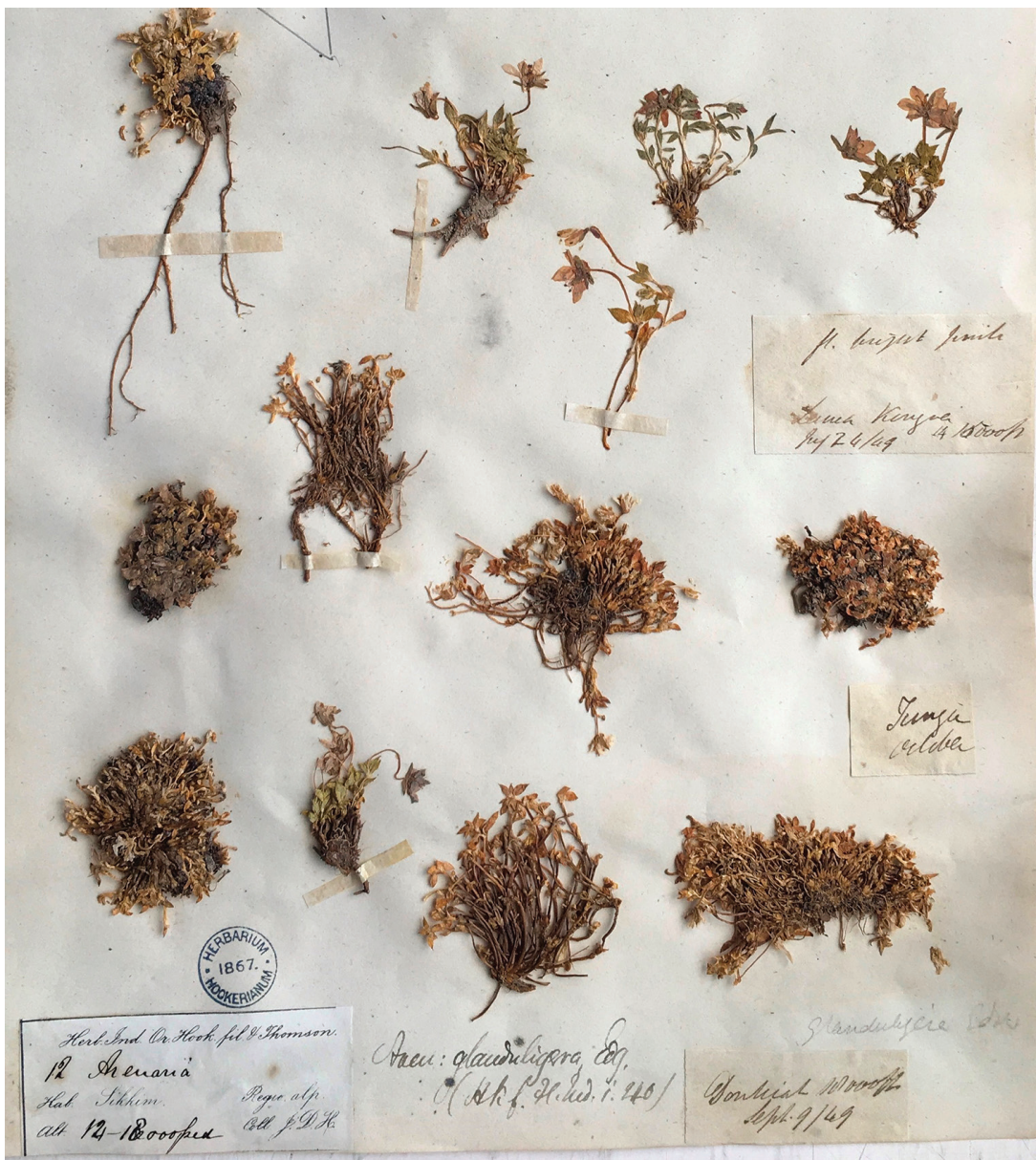

Figure 3. Syntype of Shivparvatia glanduligera (Edgew.) Pusalkar \& D.K. Singh from Sikkim (J.D. Hooker s.n., K). 


\section{Typification}

Shivparvatia glanduligera (Edgew.) Pusalkar \& D.K. Singh, J. Jpn. Bot. 90: 84. 2015 Figs 2-4

三 Arenaria glanduligera Edgew. in Edgew. \& Hook. f., Fl. Brit. India 1: 240.1874.

Type. Lectotype (designated here): Kashmir, H. Falconer s.n. (K000742189, Fig. 2); Remaining syntypes: INDIA. Interior of Sikkim, 14,000-18,000 ft, J.D. Hooker s.n. (K, Fig. 3); Kumaon, Barji Kang pass, 14,500 ft, R. Strachey \& J.E. Winterbottom s.n. (K, Fig. 4).

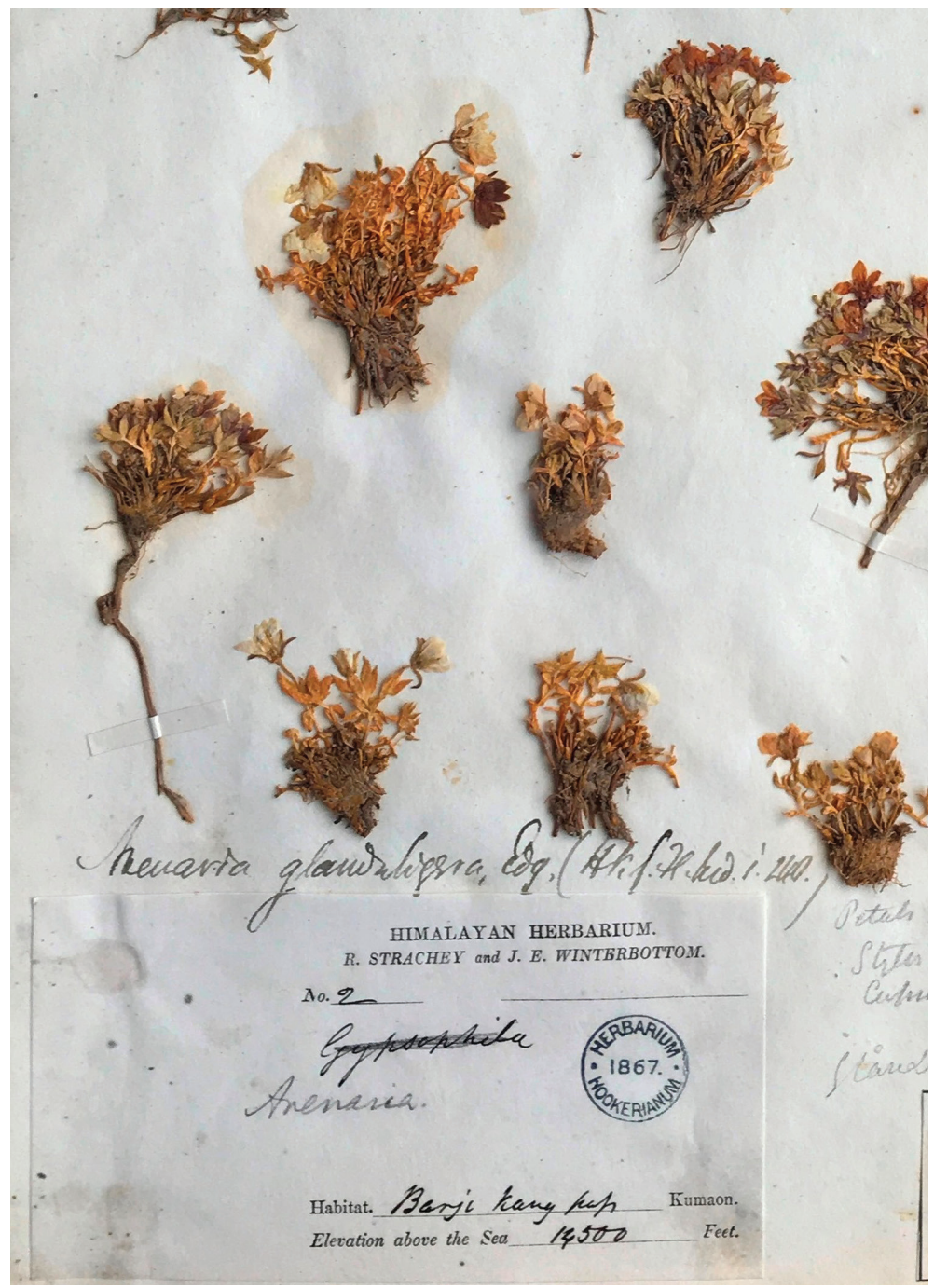

Figure 4. Syntype of Shivparvatia glanduligera (Edgew.) Pusalkar \& D.K. Singh from Kumaon (R. Strachey \& J.E. Winterbottom s.n., K). 
Note. Morphologically, S. glanduligera can be easily distinguished from S. ciliolata by its glandular pubescence, prominent disc gland, not pure white and usually violet petals, and scarious sepal margin. In contrast, the latter is characterized by its ciliate pubescence, small disc gland, entirely pure white petals, and thickened sepal margin (Wu et al. 2001; Pusalkar and Singh 2015).

\section{Acknowledgements}

The authors are indebted to the curators of the herbaria E, GH and $\mathrm{K}$ for providing specimen images. We also thank Dr. Ian Turner from Royal Botanic Gardens, Kew, for providing specimen images of Arenaria glanduligera. This study was financially supported by the National Natural Science Foundation of China (Grant no. 31872646) and the Natural Science Foundation of Guangdong Province, China (2019A1515011695).

\section{References}

Edgeworth MP, Hooker JD (1874) Arenaria. In: Hooker JD (Ed.) The Flora of British India 1(2). L. Reeve, London, 235-242.

Greenberg AK, Donoghue MJ (2011) Molecular systematics and character evolution in Caryophyllaceae. Taxon 60(6): 1637-1652. https://doi.org/10.1002/tax.606009

Harbaugh DT, Nepokroeff M, Rabeler RK, McNeill J, Zimmer EA, Wagner WL (2010) A new lineage-based tribal classification of the family Caryophyllaceae. International Journal of Plant Sciences 171(2): 185-198. https://doi.org/10.1086/648993

McNeill J (1962) Taxonomic studies in the alsinoideae. I. Generic and infra-generic groups. Notes from the Royal Botanic Garden Edinburgh 24: 79-155.

Pusalkar PK, Singh DK (2015) Taxnomic rearrangement of Arenaria (Caryophyllaceae) in Indian Western Himalaya. Shokubutsu Kenkyu Zasshi 90: 77-91.

Sadeghian S, Zarre S, Rabeler RK, Heubl G (2015) Molecular phylogenetic analysis of Arenaria (Caryophyllaceae: Tribe arenarieae) and its allies inferred from nuclear DNA internal transcribed spacer and plastid DNA rps 16 sequences. Botanical Journal of the Linnean Society 178(4): 648-668. https://doi.org/10.1111/boj.12293

Wu ZY, Zhou LH, Wagner WL (2001) Arenaria. In: Wu ZY, Raven PH (Eds) Flora of China 6. Science Press \& Missouri Botanical Garden Press, Beijing \& St. Louis, 40-66. 